\title{
PEDOT:PSS-Coated Polybenzimidazole Electroconductive Nanofibers for Biomedical Applications
}

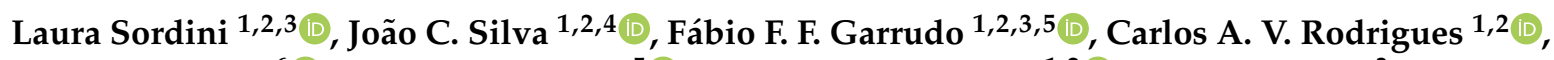 \\ Ana C. Marques ${ }^{6}\left(\mathbb{D}\right.$, Robert J. Linhardt ${ }^{5} \mathbb{D}^{\circ}$, Joaquim M. S. Cabral 1,2 ${ }^{\mathbb{D}}$, Jorge Morgado ${ }^{3, *}$ \\ and Frederico Castelo Ferreira $1,2, *$ (D)
}

Citation: Sordini, L.; Silva, J.C.; Garrudo, F.F.F.; Rodrigues, C.A.V.; Marques, A.C.; Linhardt, R.J.; Cabral, J.M.S.; Morgado, J.; Ferreira, F.C. PEDOT:PSS-Coated

Polybenzimidazole Electroconductive Nanofibers for Biomedical

Applications. Polymers 2021, 13, 2786.

https://doi.org/10.3390/polym13162786

Academic Editors: Jin-Jia Hu and Solaiman Tarafder

Received: 18 July 2021

Accepted: 9 August 2021

Published: 19 August 2021

Publisher's Note: MDPI stays neutral with regard to jurisdictional claims in published maps and institutional affiliations.

Copyright: (C) 2021 by the authors Licensee MDPI, Basel, Switzerland. This article is an open access article distributed under the terms and conditions of the Creative Commons Attribution (CC BY) license (https:/ / creativecommons.org/licenses/by/ $4.0 /)$.
1 iBB - Institute for Bioengineering and Biosciences and Department of Bioengineering, Instituto Superior Técnico, Universidade de Lisboa, Av. Rovisco Pais, 1049-001 Lisboa, Portugal; laura.sordini@tecnico.ulisboa.pt (L.S.); joao.f.da.silva@tecnico.ulisboa.pt (J.C.S.); fabio.garrudo@tecnico.ulisboa.pt (F.F.F.G.); carlos.rodrigues@tecnico.ulisboa.pt (C.A.V.R.); joaquim.cabral@tecnico.ulisboa.pt (J.M.S.C.)

2 Associate Laboratory i4HB-Institute for Health and Bioeconomy, Instituto Superior Técnico, Universidade de Lisboa, Av. Rovisco Pais, 1049-001 Lisboa, Portugal

3 Instituto de Telecomunicações and Department of Bioengineering, Instituto Superior Técnico, Universidade de Lisboa, Av. Rovisco Pais, 1049-001 Lisboa, Portugal

4 CDRSP - Centre for Rapid and Sustainable Product Development, Polytechnic Institute of Leiria, Rua de Portugal-Zona Industrial, 2430-028 Marinha Grande, Portugal

5 Center for Biotechnology \& Interdisciplinary Studies, Department of Chemistry \& Chemical Biology, Rensselaer Polytechnic Institute, Troy, NY 12180, USA; linhar@rpi.edu

6 CERENA, Department of Chemical Engineering, Instituto Superior Técnico, Universidade de Lisboa, Av. Rovisco Pais, 1049-001 Lisboa, Portugal; ana.marques@tecnico.ulisboa.pt

* Correspondence: jmfmorgado@tecnico.ulisboa.pt (J.M.); frederico.ferreira@tecnico.ulisboa.pt (F.C.F.)

Abstract: Bioelectricity drives several processes in the human body. The development of new materials that can deliver electrical stimuli is gaining increasing attention in the field of tissue engineering. In this work, novel, highly electrically conductive nanofibers made of poly $\left[2,2^{\prime}-\right.$ m-(phenylene)-5, $5^{\prime}$-bibenzimidazole] (PBI) have been manufactured by electrospinning and then coated with cross-linked poly (3,4-ethylenedioxythiophene) doped with poly (styrene sulfonic acid) (PEDOT:PSS) by spin coating or dip coating. These scaffolds have been characterized by scanning electron microscopy (SEM) imaging and attenuated total reflectance Fourier-transform infrared (ATR-FTIR) spectroscopy. The electrical conductivity was measured by the four-probe method at values of $28.3 \mathrm{~S} \cdot \mathrm{m}^{-1}$ for spin coated fibers and $147 \mathrm{~S} \cdot \mathrm{m}^{-1}$ for dip coated samples, which correspond, respectively, to an increase of about $10^{5}$ and $10^{6}$ times in relation to the electrical conductivity of PBI fibers. Human bone marrow-derived mesenchymal stromal cells (hBM-MSCs) cultured on the produced scaffolds for one week showed high viability, typical morphology and proliferative capacity, as demonstrated by calcein fluorescence staining, 4',6-diamidino-2-phenylindole (DAPI)/Phalloidin staining and MTT [3-(4,5-dimethylthiazol-2-yl)-2,5 diphenyl tetrazolium bromide] assay. Therefore, all fiber samples demonstrated biocompatibility. Overall, our findings highlight the great potential of PEDOT:PSS-coated PBI electrospun scaffolds for a wide variety of biomedical applications, including their use as reliable in vitro models to study pathologies and the development of strategies for the regeneration of electroactive tissues or in the design of new electrodes for in vivo electrical stimulation protocols.

Keywords: electroconductive; nanofibers; electrospinning; PBI; PEDOT:PSS; mesenchymal stem cells

\section{Introduction}

Bioelectricity drives several biological processes, including cell and tissue growth/ development, wound healing and tissue regeneration [1]. Bioelectrical triggered cell signaling affects transcriptional cascades, and thus can influence changes in cell fate, potentially 
affecting processes such as proliferation, differentiation, migration, morphology and apoptosis [2]. Aside from excitable cells, such as neurons and muscle cells, there are several other cell types that respond to electric fields in the human body, such as fibroblasts [3], osteoblasts [4], chondrocytes [5] and mesenchymal stromal cells (MSCs) [6]. MSCs have been considered a promising cell source for developing novel cell-based therapies, mainly due to their availability from a wide variety of tissues, high proliferative capacity, lowimmunogenicity and beneficial immunomodulatory/trophic properties [7]. Regarding tissue regeneration, external electrical stimulation has been shown to promote bone healing both in animal experiments and clinical treatments [8]. Additionally, preclinical and clinical studies have shown superior healing of cartilage defects with MSCs after the application of electrical current $[9,10]$.

Novel electrically conductive biocompatible materials, capable of delivering electrical stimuli to cells have been developed, envisaging new approaches for regenerative medicine. Such materials can be directly implanted for cell stimulation in vivo, used to guide cell differentiation in vitro, or employed as vehicles to deliver biochemical agents when electrically stimulated [11]. As such, when used as tissue substitutes (alone or in combination with electrical stimulation), these materials can potentially facilitate the healing process of diseased or damaged tissues. The most commonly used electrically conductive materials in biomedical applications are metals, carbon nanotubes and conductive polymers [12]. Among these, electrically conductive polymers are the most versatile as they can be easily functionalized for a specific application and can be processed using various manufacturing techniques, such as casting, 3D melt-extrusion, electrospinning and 3D printing [13]. Particularly, conjugated polymers with a $\pi$-conjugated backbone can be designed/modified to display high electrical conductivity, outstanding photophysical properties and excellent biocompatibility [14]. The most widely investigated conjugated polymers for biomedical applications include polypyrrole (PPy), polyaniline (PANI), polythiophene (PTh) and its derivatives such as poly (3,4-ethylenedioxythiophene) (PEDOT). When oxidized, PEDOT is usually stabilized with a polyelectrolyte, polystyrene sulfonate (PSS), and the resultant PEDOT:PSS blend presents high electrical conductivities [15,16].

Polymeric nanofibers have great potential as tissue engineering scaffolds, since they can closely mimic the nanoscale structural features of the native extracellular matrix (ECM). Moreover, the high porosity, pore interconnectivity and surface area provided by electrospun scaffolds promote cell adhesion, migration and proliferation and enable efficient nutrient supply and waste removal $[17,18]$. Electrospun nanofibrous scaffolds have been employed in numerous tissue regeneration applications including skin, muscles, bone, cartilage, nerves and blood vessels [19-21]. Electrically conductive nanofibers can provide both topographical and electrical cues, being particularly promising to modulate the behavior of the cells [22]. In particular, both neurogenic and chondrogenic differentiation of human MSCs were reported to be enhanced upon electrical stimulation, when such cells were cultured on electrically conductive scaffolds without chemical cues [23,24]. Prabhakaran et al. presented a comparative study to evaluate nerve stem cell growth with electrical stimulation (ES) on conductive and non-conductive nanofibers and demonstrated that, when using a conducting polymer, high proliferation was obtained on nanofibers with a small diameter and high tensile strength [25]. However, the production of an electrospun nanofiber scaffold with a narrow fiber diameter distribution and morphology still remains challenging. Further studies on nanofibers are needed to obtain effective 3D matrixes for MSC culturing and differentiation and the application of external stimuli (e.g., electrical) to help identify a beneficial tool for use in regenerative medicine.

Previous results from our group have demonstrated the superior properties of water stable films made of PEDOT:PSS CLEVIOS P VP.AI 4083 (1:6 PEDOT:PSS weight ratio) crosslinked with (3-glycidyloxypropyl) trimethoxysilane (GOPS) with electrical conductivity in the range of several tens of $\mathrm{S} \cdot \mathrm{m}^{-1}$. Such highly conductive films were then successfully used to support neural stem cells differentiation under electrical stimula- 
tion [16]. However, processing PEDOT:PSS into robust 3D fibers of nanoscale diameter, without losing its conductivity, is a very challenging task.

In the current study, PEDOT:PSS cross-linked with GOPS was investigated, for the first time, as a coating to increase the conductivity and the biocompatibility of electrospun fibrous scaffolds made of a semi-conjugated polymer, polybenzimidazole (PBI).

PBI is a fully aromatic heterocyclic polymer (Figure 1), chemically stable and resistant to heat and mechanical load. PBI is rarely used in the context of medical applications and therefore it is not an obvious choice as carrier electrospun fibers to be coated with PEDOT:PSS. A recent study by our group has demonstrated, for the first time, a superior biocompatibility property of polybenzimidazole (PBI) electrospun nanofibers to support neural stem cell culture [26]. In our study [26], we were able to increase PBI nanofiber conductivity through doping with different acids. Nonetheless, the highest value obtained was far below $1 \mathrm{~S} \cdot \mathrm{m}^{-1}$. PBI is easily electrospun to form nanofibers, that can be protonated upon contact with the acidic PEDOT:PSS dispersion $(\mathrm{pH} \approx 1-2)$, potentially contributing to ionic interactions with PEDOT:PSS. Moreover, PBI has another important advantage, enabling the stabilization of the coating with PEDOT:PSS solution. For coating stabilization, the material has to undergo an annealing treatment at $150{ }^{\circ} \mathrm{C}$, a temperature that is higher than the melting temperature of several polymers, but suitable for PBI, which is thermostable up to $400{ }^{\circ} \mathrm{C}$ [27].
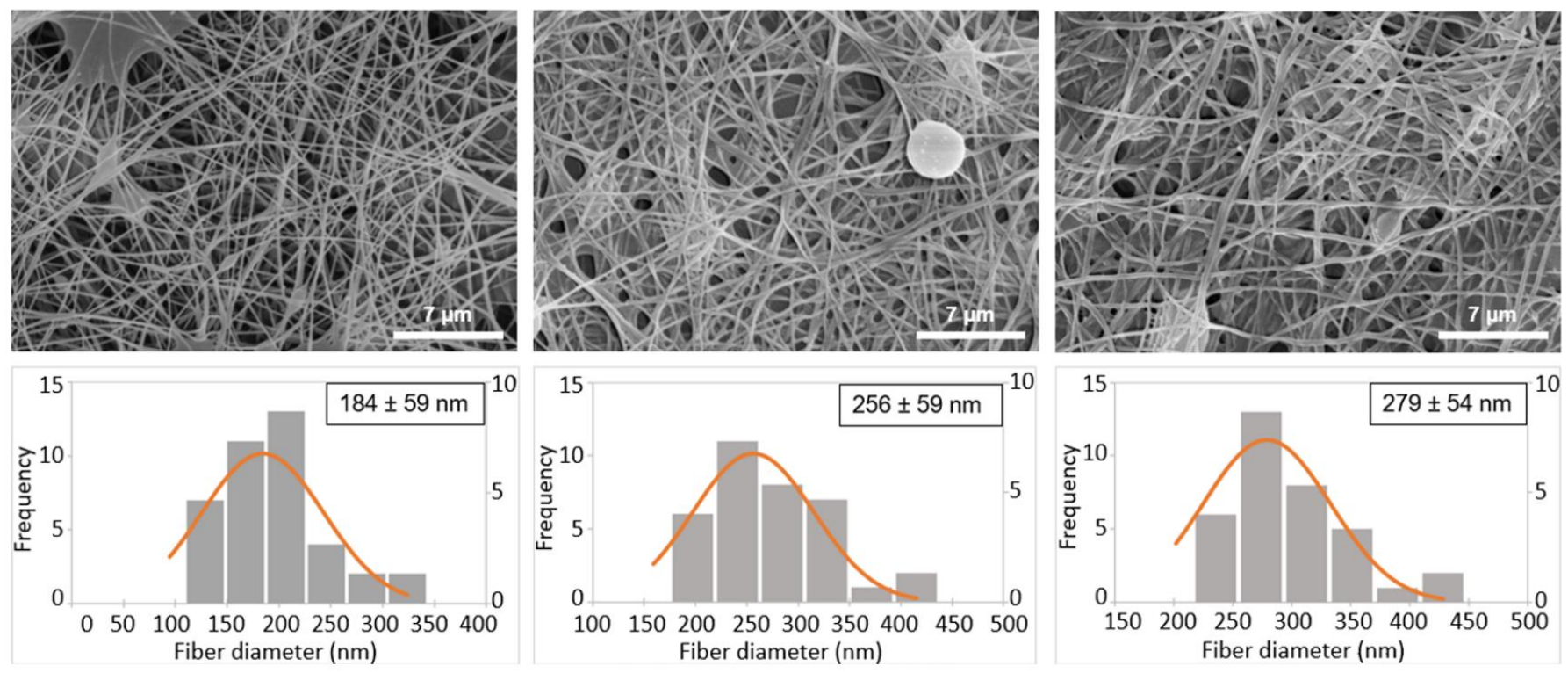<smiles>CCc1nc2cc(-c3ccc4nc(-c5cccc(C(C)(C)C)c5)[nH]c4c3)ccc2[nH]1</smiles>

PBI<smiles>CC(C)(C)c1sc(C(C)(C)C)c2c1OCCO2</smiles><smiles>CC(C)(C)C(C)(C)c1ccc(S(=O)(=O)O)cc1</smiles>

PEDOT:PSS

Figure 1. SEM images (top) and respective fiber diameter distributions (middle) of pristine electrospun PBI, cross-linked PEDOT:PSS-spin coated PBI and cross-linked PEDOT:PSS-dip coated PBI nanofibers. Scale bar: $7 \mu \mathrm{m}$. The discreet histogram values are represented on the left $y y$-axis and the normal probability density function each mean and standard deviation are represented on the right $y y$-axis. Chemical structures of poly $\left[2,2^{\prime}-\mathrm{m}\right.$-(phenylene)-5, $5^{\prime}$-bibenzimidazole] (PBI) and poly (3,4-ethylenedioxythiophene) doped with poly (styrene sulfonic acid) (PEDOT:PSS) are shown in the (bottom) panel. 
The aim of this work is the fabrication of novel PBI-based electrospun nanofibrous scaffolds with enhanced electroconductivity through coating with PEDOT:PSS crosslinked with GOPS. Two different coating methods (spin coating vs. dip coating) were used to generate PEDOT:PSS-coated PBI nanofibers. The scaffolds obtained were characterized in terms of their morphology, fiber diameter, electrical conductivity and Fourier-transform infrared (FTIR) spectra. Moreover, the biocompatibility of the developed scaffolds was assessed in vitro using human bone marrow-derived MSCs (hBM-MSCs). hBM-MSC were selected considering their relevance in cell therapy and tissue engineering strategies and the final goal to produce biocompatible nanofibers with adequate electrical conductivity for biomedical applications. To our knowledge, this is the first study combining PEDOT:PSS with PBI electrospun nanofibers to generate biocompatible scaffolds with enhanced electrical conductivity.

\section{Materials and Methods}

\subsection{Preparation of Material Solutions}

Celazole $^{\circledR}$ S26 solution, containing 26 wt \% PBI and 1.5 wt \% lithium chloride in N,N-dimethylacetamide (DMAc), was purchased from PBI Performance Products, Inc. (Charlotte, NC, USA). This starting solution was diluted to $13 \%$ using DMAc (SigmaAldrich, St. Louis, MO, USA), and the mixture was left overnight under mechanical stirring to obtain a homogeneous solution. The aqueous PEDOT:PSS-coating dispersion (used for PBI fibers coating) was prepared by addition of ethylene glycol (EG,1:4 EG to PEDOT:PSS volume ratio), dodecylbenzenesulfonic acid (DBSA, $0.5 \mu \mathrm{L} \cdot \mathrm{mL}^{-1}$ ), and GOPS $\left(10 \mu \mathrm{L} \cdot \mathrm{mL}^{-1}\right)$ to PEDOT:PSS regular dispersion (solid content 1.3-1.7\%, CLEVIOS P AI 4083, Heraeus, Germany), which has been filtered using a $0.45 \mu \mathrm{M}$ filter [16]. DMAc, EG, DBSA, hydrochloric acid $(\mathrm{HCl})$, isopropanol and GOPS were purchased from Sigma-Aldrich, St. Louis, MO, USA and used as received.

\subsection{Production of Electrospun PBI Nanofibers}

PBI 13 wt \% solution in DMAc was loaded into a $10 \mathrm{~mL}$ Luer lock syringe placed in a syringe pump and connected to a polytetrafluoroethylene (PTFE) tube, which was attached on the other end to a $21 \mathrm{G}$ needle. The electrospinning procedure was performed using a vertical set-up and a flat aluminum collector placed at a distance of $11 \mathrm{~cm}$ from the needle tip. The electrospinning operating conditions were $20 \mathrm{kV}$ direct current (DC) applied voltage and a controlled flow rate of $0.3 \mathrm{~mL} \cdot \mathrm{h}^{-1}$. The fibers were electrospun directly on clean glass coverslips placed on the top of the collector. The process was carried out at room temperature $\left(21-24{ }^{\circ} \mathrm{C}\right)$ and with a relative humidity of $50 \%$. Finally, the collected fibers were left to air dry overnight.

\subsection{Coating of Electrospun PBI Nanofibers with PEDOT:PSS}

Two different coating methods, spin coating and dip coating, were tested in this work. The composition of the aqueous PEDOT:PSS coating dispersion, used in both methods and comprising PEDOT:PSS and cross-linking agents, is described in Section 2.1. In the spin coated method the aqueous PEDOT:PSS-coating dispersion was spun (Spin-Coater KW-4A, Chemat Technology, Northridge, CA, USA) on the PBI nanofiber meshes at a spinning speed of $1800 \mathrm{rpm}$ for $60 \mathrm{~s}$. In the dip coated method, the PBI nanofibers were immersed in the aqueous PEDOT:PSS coating dispersion for $24 \mathrm{~h}$, after which the excess of coating solution was allowed to drain out of the sample. In both methods, the coated fibers were annealed at $150{ }^{\circ} \mathrm{C}$ for 2 min to obtain the final cross-linked PEDOT:PSS-coated PBI nanofiber meshes.

\subsection{Scanning Electron Microscopy}

The morphology of the electrospun nanofiber mats was evaluated by scanning electron microscopy (SEM, JEOL, JSM-7001F model, Japan) at an accelerating voltage of $20 \mathrm{kV}$. Prior to imaging, the samples were coated with a $30 \mathrm{~nm}$ layer of gold/palladium (Polaron 
model E5100 sputter coater, Quorum Technologies, UK). The average fiber diameter of the electrospun scaffolds was determined by measuring 40 individual fibers from at least 5 different SEM images (5000X) using ImageJ software (ImageJ 1.51f, National Institutes of Health, Bethesda, MD, USA).

\subsection{Attenuated Total Reflectance Fourier-Transform Infrared (ATR-FTIR) Spectroscopy}

The ATR-FTIR analysis was performed using a Spectrum Two FT-IR Spectrometer (Perkin-Elmer, Waltham, MA, USA). The samples submitted to ATR-FTIR were: (i) pristine electrospun PBI fibers, (ii) cross-linked PEDOT:PSS-spin coated PBI fibers, (iii) cross-linked PEDOT:PSS-dip coated PBI fibers, (iv) non cross-linked PEDOT:PSS pellets, and (v) crosslinked (PEDOT:PSS:GOPS) pellets. Transmittance spectra were obtained over the region from 500 to $4000 \mathrm{~cm}^{-1}$, with a resolution of $4 \mathrm{~cm}^{-1}$ and an accumulation of 8 scans. Pellets were prepared by simple drop casting allowing the water evaporation at $70{ }^{\circ} \mathrm{C}$ (overnight) and labeled as PEDOT:PSS or PEDOT:PSS:GOPS, respectively, when made from regular PEDOT:PSS dispersion or from the aqueous PEDOT:PSS-coating dispersion (see Section 2.3 for composition), respectively. Both pellets were then annealed at $150{ }^{\circ} \mathrm{C}$ for $2 \mathrm{~min}$.

\subsection{Four-Point Probe Electroconductivity Measurements}

Four stripes of gold were deposited on the samples by physical vapor deposition (PVD), using an Edwards E306A thermal evaporator, across the entire surface and with equal distance from each other. Electrodes were put in direct contact with the gold stripes. Measurements were performed in triplicate $(n=3)$ and averaged. The resistance $(R)$ was estimated according to Ohm's law $(R=\Delta \mathrm{V} / \mathrm{I})$, correlating the difference of electrical potential measured between the two inner contacts for different values of electrical current applied at the outer contacts. At a constant temperature, the: resistivity $(\sigma)$ and conductivity $(\sigma)$ can be calculated, respectively, from Equations (1) and (2):

$$
\begin{array}{cc}
R=\rho(L / A) & \left(\mathrm{S}^{-1} \text { or } \Omega\right) \\
\sigma=1 / \rho & \left(\mathrm{S} \cdot \mathrm{cm}^{-1}\right)
\end{array}
$$

where $L$ is the distance between the two inner contacts and $A$ is the sample cross-section (i.e., sample thickness times the sample width). For thickness measurements, the sample was placed on a glass support, cut with a scalpel all of the way through to the glass surface, and the depth of the cut was estimated by profilometry (Bruker's Dektak ${ }^{\circledR} 3.21$ Profilometer (Bruker, Billerica, MA, USA) upon surface scanning perpendicular to the cut.

\subsection{Cell Culture}

hBM-MSCs were isolated from bone marrow aspirates following a protocol previously developed in our group [28]. The aspirates were obtained from a healthy donor (male, 36 years) upon informed consent, with the approval of the ethics committee of Instituto Português de Oncologia Francisco Gentil. Isolated hBM-MSCs were cultured using lowglucose Dulbecco's Modified Eagle's Medium (DMEM, Gibco, ThermoFisher, Waltham, MA, USA) supplemented with 10\% v/v fetal bovine serum MSC-qualified (FBS, Life Technologies, Carlsbad, CA, USA) and 1\% $v / v$ antibiotic-antimycotic (Anti-Anti, ThermoFisher, Waltham, MA, USA), and kept at $37^{\circ} \mathrm{C}$ and $5 \% \mathrm{CO}_{2}$ in humidified atmosphere. All the experiments were performed using cells between passages P4-P6 and the culture medium was fully replaced every 3-4 days.

\section{8. hBM-MSCs' Seeding on Electrospun Scaffolds}

The three types of electrospun scaffolds prepared in this work (i.e., pristine electrospun PBI nanofibers, cross-linked PEDOT:PSS-spin coated PBI nanofibers and cross-linked PEDOT:PSS-dip coated PBI nanofibers) were placed in ultra-low attachment 24-well culture plates (Corning, NY, USA) and sterilized with 1\% Anti-anti solution in PBS (Gibco, ThermoFisher, Waltham, MA, USA) for $24 \mathrm{~h}$. The samples were then washed twice with PBS 
and left immersed in culture medium DMEM $+10 \%$ FBS $+1 \%$ Anti-anti for $3 \mathrm{~h}$. Afterwards, the culture medium was removed and scaffolds were seeded with a density of 40,000 hBM-MSCs per scaffold. The cells were left for $2 \mathrm{~h}$ at $37^{\circ} \mathrm{C}$ and $5 \% \mathrm{CO}_{2}$ without culture medium to promote initial cell attachment to the scaffolds. Culture medium was fully renewed every 3-4 days.

\subsection{Evaluation of the Viability and Proliferation of hBM-MSCs on PEDOT:PSS-Coated PBI Electrospun Scaffolds}

The viability and proliferation of hBM-MSCs on the three scaffolds prepared (pristine electrospun PBI fibers, cross-linked PEDOT:PSS-spin coated PBI fibers and crosslinked PEDOT:PSS-dip coated PBI fibers) were evaluated at days 1 and 7 by assessing cell metabolic activity using the MTT (3-(4,5-dimethylthiazol-2-yl)-2-5 diphenyl tetrazolium bromide, MTT Cell Growth Assay Kit, Sigma-Aldrich, St. Louis, MO, USA) assay following the manufacturer's guidelines. Briefly, after washing the samples with PBS, the cells were incubated with MTT solution ( $1 \mathrm{mg} \cdot \mathrm{mL}^{-1}$, prepared in PBS) and incubated for $4 \mathrm{~h}$ at $37^{\circ} \mathrm{C}$ as previously described $[29,30]$. The resulting formazan salt was then dissolved using a solution of $0.1 \mathrm{M} \mathrm{HCl}$ in isopropanol under agitation for $5 \mathrm{~min}$, and the absorbance values of the resultant solutions were measured using a plate reader (Infinite M200 PRO, TECAN, Switzerland) at $570 \mathrm{~nm}$. Three scaffolds $(n=3)$ were used for each condition and the absorbance values were measured in triplicate. Acellular scaffolds (i.e., scaffolds that have not been seeded with cells) were used as blank controls.

The viability of hBM-MSCs on the scaffolds was also confirmed by calcein staining at days 1 and 7. For that, cells were washed once with PBS and incubated with a calcein staining solution ( $4 \mathrm{mM}$ in PBS, ThermoFisher, Waltham, MA, USA) for $40 \mathrm{~min}$ at $37{ }^{\circ} \mathrm{C}$. Afterwards, the cells were washed twice with PBS and imaged using a fluorescence microscope (LEICA DMI3000B, Leica Microsystems, Germany) equipped with a digital camera (Nikon DXM1200F, Nikon Instruments Inc., Japan).

\subsection{Assessment of hBM-MSCs' Morphology on PEDOT:PSS-Coated PBI Electrospun Scaffolds}

To evaluate the morphology of the cells on the electrospun scaffolds, DAPI/Phalloidin staining was performed at days 1 and 7. Cells were fixed for $30 \mathrm{~min}$ with $4 \%(v / v)$ paraformaldehyde (PFA, Santa Cruz Biotechnology, Dallas, TX, USA) solution (in PBS) and permeabilized with $0.1 \%$ Triton X-100 (Sigma-Aldrich, St. Louis, MO, USA) for $10 \mathrm{~min}$. Then, the samples were incubated with Phalloidin-TRITC $\left(5 \mu \mathrm{g} \cdot \mathrm{mL}^{-1}\right.$, Sigma-Aldrich, St. Louis, MO, USA) for $45 \mathrm{~min}$ in the dark, washed twice with PBS, and counterstained with DAPI (1.5 $\mu \mathrm{g} \cdot \mathrm{mL}^{-1}$, Sigma-Aldrich, St. Louis, MO, USA) for $5 \mathrm{~min}$ in the dark. Finally, the cells were washed again twice with PBS and the staining was observed in a fluorescence microscope (LEICA DMI3000B, Leica Microsystems, Germany) equipped with a digital camera (Nikon DXM1200F, Nikon Instruments Inc., Japan).

\section{Results and Discussion}

\subsection{Morphological Characterization of Electrospun Scaffolds}

In this work, we tested two different methods, spin coating and dip coating, to coat the electrospun PBI fibers with PEDOT:PSS aiming to increase the electroconductivity of the obtained fiber mat. After PEDOT:PSS coating, followed by thermal annealing, a porous nanoweb was obtained. The morphology of the electrospun fibers mats was analyzed by SEM (Figure 1). The fibers of neat PBI are randomly oriented, homogeneous, showing few defects, and have an average diameter of $184 \pm 59 \mathrm{~nm}$. This average diameter value is similar to that obtained by Jahangiri et al. [31], but slightly larger than the values obtained in previous works $[26,32]$, which we attribute to the milder electrospinning conditions used in the present study, namely the lower voltage and tip-to-collector distance. After coating, the diameter of the fibers increased to $256 \pm 59 \mathrm{~nm}$ and $279 \pm 54 \mathrm{~nm}$, for spin coated and dip coated fibers, respectively. The increase in fiber diameter suggests that both coating methods are effective to modify the PBI surface. The dip coated samples exhibit a 
slightly higher diameter than for the spin coating ones, which reflects the adsorption of more material on the fibers surface, in agreement with previously reported studies [33].

The diameters of the obtained fibers are within the nanometer range, all below $300 \mathrm{~nm}$. The fiber diameter size is a very important factor for tissue engineering applications employing MSCs. For example, Lü and colleagues [34] compared poly(3-hydroxybutyrate-co3-hydroxyvalerate) (PHBV) electrospun fibers with diameters in the micrometer $(2110 \mathrm{~nm})$ and nanometer ( 383 or $600 \mathrm{~nm}$ ) range and observed that nanometer size fibers promote higher attachment and proliferation of BM-MSCs in the scaffold, which is important for the success of tissue engineering strategies. A similar trend was also observed by Jia and colleagues [35] for BM-MSCs cultured on poly (L-lactic acid)/ collagen (PLLA/Coll) nanofibers targeting vascular tissue regeneration, and by Yang and colleagues [36] for neural stem cells cultured on PLLA nano/micro fibrous scaffolds.

\subsection{ATR-FTIR Analysis}

The ATR-FTIR spectra of the materials are shown in Figure 2. ATR-FTIR spectrum of pristine electrospun PBI fibers (Figure 2Aa) displays the characteristic peaks of PBI structure corresponding to substituted benzene rings (out-of-plane bend vibrations for the $\mathrm{C}-\mathrm{H}$ bonds at $691 \mathrm{~cm}^{-1}$ and $799 \mathrm{~cm}^{-1}$ ), to imidazole rings (breathing mode at $1289 \mathrm{~cm}^{-1}$ ) and benzimidazole rings (in-plane deformation at $1444 \mathrm{~cm}^{-1}$ ). The peak at $1618 \mathrm{~cm}^{-1}$ corresponds to $\mathrm{C}=\mathrm{N}$ stretching, also present in the imidazole groups. The region between 2400 and $3955 \mathrm{~cm}^{-1}$ is attributed to amine groups, widely distributed through the polymer's structure [26,37]. The presence of the solvent used for electrospinning, DMAc, was not detected.
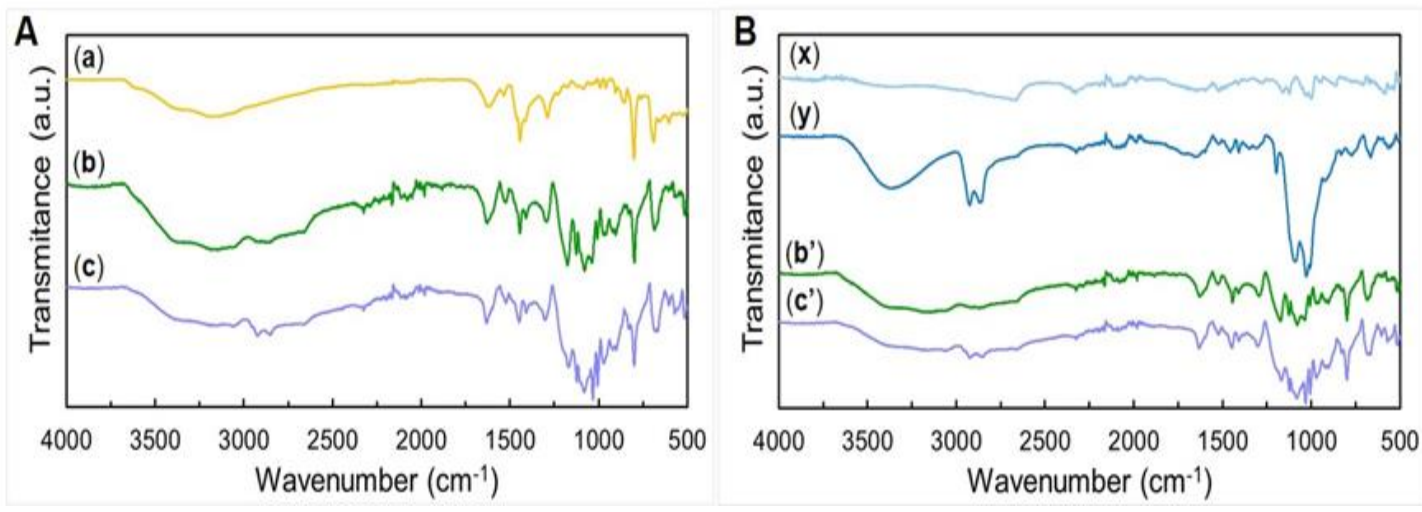

Figure 2. ATR-FTIR spectra of the various samples analyzed. (A) Spectra normalized to peak $799 \mathrm{~cm}^{-1}$ of (a) PBI electrospun fibers, and PEDOT:PSS/PBI obtained by (b) spin coating and (c) dip coating. (B) Spectra normalized to peak $2324 \mathrm{~cm}^{-1}$ of PEDOT:PSS/PBI samples obtained by $\left(b^{\prime}\right)$ spin coating and $\left(c^{\prime}\right)$ dip coating, $(x)$ PEDOT:PSS pellet and (y) PEDOT:PSS pellet with GOPS.

As a first approach, we normalized the peak intensities of all the PBI-containing fibers to the common peak at $799 \mathrm{~cm}^{-1}$ (Figure 2A). A further analysis based on normalization of spectra to the common at peak $1443 \mathrm{~cm}^{-1}$ can be found on supplementary information (Figure S1A) allowing further detailed discussion on PEDOT:PSS andGOPS contribution to the spectra.

The spectra of the cross-linked PEDOT:PSS-coated PBI fiber samples obtained by spin and dip coating are depicted in Figure 2A b,A c, respectively. They combine the characteristic peaks of the starting materials, PBI and PEDOT:PSS with GOPS, confirming that the coating was successful for both spin and dip coated samples. Thus, peaks at $799 \mathrm{~cm}^{-1}$, $1298 \mathrm{~cm}^{-1}, 1444 \mathrm{~cm}^{-1}$ and $1632 \mathrm{~cm}^{-1}$ are attributed to PBI, and peaks at $1034 \mathrm{~cm}^{-1}$, $1083 \mathrm{~cm}^{-1}$ and the double peaks at $2855 / 2924 \mathrm{~cm}^{-1}$ are attributed to PEDOT:PSS crosslinked with GOPS. The region between 2400 and $3955 \mathrm{~cm}^{-1}$ arises from an overlap of the corresponding regions of PBI and PEDOT:PSS with GOPS. This region is associated with the hydroxyl and amine groups present in either material, and ultimately with residual free water present/absorbed by the samples [38,39]. The broad peak at $1643 \mathrm{~cm}^{-1}$ from PEDOT:PSS 
with GOPS slightly overlaps the sharp $1444 \mathrm{~cm}^{-1}$ peak of imidazole/benzimidazole rings of PBI in both dip coated and spin coated samples. The overlay seen of both PBI and PEDOT peaks in our PEDOT:PSS-coated PBI fibers is consistent with the phase separation in both the dip-coated and spin-coated fibers and confirms that the coating was successful.

In the PEDOT:PSS-dip coated PBI fibers (Figure 2Ac), the double peak $2855 / 2924 \mathrm{~cm}^{-1}$ is more pronounced than the PEDOT:PSS-spin coated PBI fibers (Figure 2Ab). In the corresponding $3000-3660 \mathrm{~cm}^{-1}$ region, we expect peaks arising not only from both amine (PBI) and hydroxyl (water) groups present in either PBI or PEDOT:PSS, but also from residual free water. In the case of PEDOT:PSS-dip coated PBI fibers, the relative intensity of this area is smaller when compared to PEDOT:PSS-spin coated PBI fibers.

To perform a better analysis of the behavior of PEDOT:PSS in all our samples without the bias resulting from PBI, we normalized the peak intensities of all PEDOT-containing samples to the common peak at $2324 \mathrm{~cm}^{-1}$ (Figure 2B). PEDOT:PSS spectra (Figure 2Bx) have two peaks at $665 \mathrm{~cm}^{-1}$ and $860 \mathrm{~cm}^{-1}$ (thiophene ring). There are also two double peaks at 998 and $1000 \mathrm{~cm}^{-1}$ (C-S bond in thiophene ring) and at 1123 and $1158 \mathrm{~cm}^{-1}$ (C-O stretching in PEDOT and sulfoxide in PSS). A broad peak is also seen at $1595 \mathrm{~cm}^{-1}$ (thiophene ring) and is also present in the spectra of PEDOT:PSS with GOPS (Figure 2By). Moreover, a peak common to all PEDOT-derived compounds tested in this work is seen at $2325 \mathrm{~cm}^{-1}$ and next to it there is a broad peak at $2656 \mathrm{~cm}^{-1}$ (alkane $\mathrm{C}-\mathrm{H}$ bonds) $[40,41]$. The spectrum of the PEDOT:PSS pellet with GOPS (Figure 2By) has a small peak at $663 \mathrm{~cm}^{-1}$ (C-S stretching in the thiophene ring), two major peaks at $1007 / 1028$ and $1092 \mathrm{~cm}^{-1}$ (sulfoxide groups in PSS), and a small peak at $1194 \mathrm{~cm}^{-1}$ (sulfonate group present in the GOPS cross-linking). At $1643 \mathrm{~cm}^{-1}$, there is a broad peak associated with the $\mathrm{C}=\mathrm{C}$ bond in the thiophene ring. A double peak at $2855 / 2924 \mathrm{~cm}^{-1}$ (C-H bond stretching and aldehyde bonds arising from GOPS cross-linking [42,43]) and a broader peak at $3357 \mathrm{~cm}^{-1}$ (2990-3640 $\mathrm{cm}^{-1}$ region) (intermolecular hydrogen bonds) can also be seen.

In the original PEDOT:PSS samples, the peak intensity of this area drastically increases with GOPS cross-linking. This is mainly due to an increase in the number of sulfoxide bonds $\left(1007 / 1028 \mathrm{~cm}^{-1}\right.$ and $\left.1092 \mathrm{~cm}^{-1}\right)$ established between PSS and GOPS, leading also to a decrease in the number of sulfonate $\left(1197\right.$ and $\left.1408 \mathrm{~cm}^{-1}\right)$ groups present. A first look at the $750-1250 \mathrm{~cm}^{-1}$ region (thiophene ring) evidences that the overall peak intensity is higher for dip coated samples than for the spin coated samples.

In the PEDOT:PSS-dip coated PBI fibers (Figure 2Bc'), the intensity of the sulfonate peak at $1197 \mathrm{~cm}^{-1}$ is smaller than the spin coated sample (Figure $\left.2 \mathrm{Bb}^{\prime}\right)$. This suggests the higher stability of the PEDOT:PSS with GOPS layers formed around the PBI fiber, since a greater amount of more stable bonds is present. Another indication of a more successful cross-linking of PEDOT:PSS in the dip coated sample is a more defined double peak at $2855 / 2924 \mathrm{~cm}^{-1}$, which is present in the original PEDOT:PSS cross-linked with GOPS.

Both samples were cross-linked in similar conditions $\left(150{ }^{\circ} \mathrm{C}, 2 \mathrm{~min}\right)$ and similar fiber diameters were obtained. We hypothesize that the longer incubation of the dip coating method is a more efficient method to deposit a stable/cross-linked PEDOT:PSS layer on the PBI fibers. A consequence of a more stable PEDOT layer is a better overall electroconductivity of the obtained PEDOT:PSS-coated PBI fibers obtained by dip coating.

The results in supplementary data further suggest a higher amount of PEDOT:PSS on fiber samples obtained by dip coating than on the ones obtained by spin coating. Both the ATR-FTIR intensity of normalized peaks (Figure S1A) and the TGA mass loss percentage (Figure S1B,C and Table S1), respectively, at wavelengths and temperatures allocated to PEDOT:PSS, are higher for fibers samples obtained by dip coating than for the ones obtained by spin coating.

\subsection{Electroconductivity Measurements}

The electrical conductivity of the electrospun scaffolds was measured using the fourprobe method. PBI nanofibers displayed a conductivity of $3.0 \times 10^{-5} \mathrm{~S} \cdot \mathrm{m}^{-1}$, which is 
consistent with values obtained previously by our group [26] and with values reported by others [44].

The PEDOT:PSS cross-linking solution used in this work was previously tested by Pires et al. in the form of films, using slightly different annealing conditions, and showed a conductivity of $5.8 \mathrm{~S} \cdot \mathrm{m}^{-1}$ [16]. The conductivity obtained for a cross-linked PEDOT:PSS film deposited on glass using the new annealing conditions $\left(150^{\circ} \mathrm{C}, 2 \mathrm{~min}\right)$ is $500 \mathrm{~S} \cdot \mathrm{m}^{-1}$, which is consistent with our most recent studies [45].

After coating with PEDOT:PSS, the conductivity of the fiber mats was determined to be $28.3 \mathrm{~S} \cdot \mathrm{m}^{-1}$ for spin coated scaffolds and $147 \mathrm{~S} \cdot \mathrm{m}^{-1}$ for dip coated ones, where the thickness used in the electrical conductivity calculations was taken as the total thickness of the materials (PBI fiber mat with PEDOT:PSS-coating layer). As these scaffolds behave as a two layer-materials, with the PBI, having a lower electrical conductivity, as a substrate, the electrical conductivity is mainly that of the PEDOT:PSS coating layer. Therefore, the intrinsic electrical conductivity of PEDOT:PSS layer, thinner than the entire scaffold, will be higher than the calculated values for the PEDOT:PSS-coated scaffolds and should approach the value of $500 \mathrm{~S} \cdot \mathrm{m}^{-1}$ mentioned above.

Accordingly, we attribute the higher conductivity values obtained for the dip coated samples in comparison with that of the spin coated sample mainly to the higher thickness of the PEDOT:PSS coating layer present, as suggested by the fiber diameter size and ATRFTIR studies in Sections 3.1 and 3.2, respectively. However, possible differences in the intrinsic electrical conductivity of the cross-linked PEDOT:PSS deposited by dip and spin coating, as a result of differences in composition, cross-linking degree and phase separation induced by the different deposition and drying conditions cannot be ruled out.

Table 1 compares the characteristics of the obtained PEDOT:PSS-coated PBI fibers with other previously reported studies on electrically conductive electrospun fibers containing PEDOT:PSS. From the comparative analysis of the studies, we may conclude that our PEDOT:PSS-coated PBI scaffolds present an interestingly high electrical conductivity and small fiber diameter. Many studies in the literature have shown that a reduction in the fiber diameter of electrospun scaffolds significantly increases cell attachment and growth, due to an increase in surface area and local curvature which results in stronger bonds between cell surface receptors and fibers [46,47]. In particular, Abedi et al. [48] have demonstrated that a lower average fiber diameter have enhanced MSCs' metabolism and proliferation on electrospun chitosan/PEDOT:PSS electrically conductive scaffolds [48].

In a previous study, culturing hMSCs on electrospun nanofibers meshes, Chen et al. fabricated bacterial cellulose nanofibers coated with PEDOT by in situ interfacial polymerization and achieved electrical conductivities of $0.1-10 \mathrm{~S} \cdot \mathrm{m}^{-1}$ [49]. Despite the differences in the coating methods used, the lower electrical conductivities obtained, in comparison to our study, might be explained by a possible difference in the amount of conductive PEDOT phase within the samples and its oxidative degree, combined with a poor electrical conductivity of about $10^{-6} \mathrm{~S} \cdot \mathrm{m}^{-1}$ of the supporting bacterial cellulose fibers, which is lower than the values reported for PBI [26] 


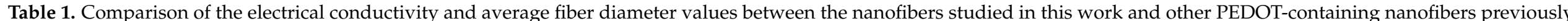

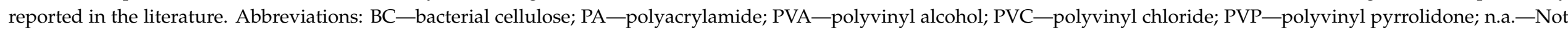
applicable.

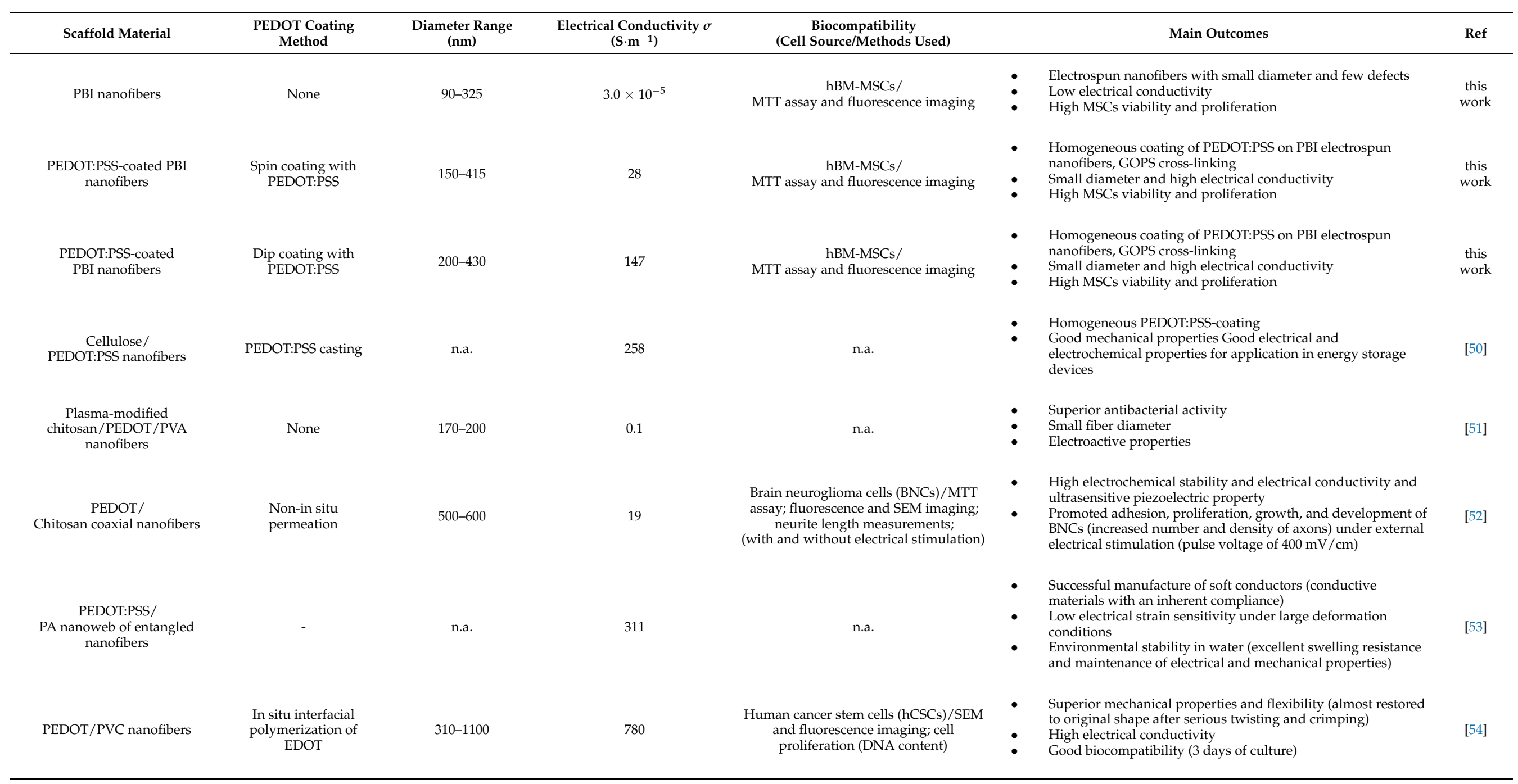


Table 1. Cont.

\begin{tabular}{|c|c|c|c|c|c|c|}
\hline Scaffold Material & $\begin{array}{l}\text { PEDOT Coating } \\
\text { Method }\end{array}$ & $\begin{array}{c}\text { Diameter Range } \\
(\mathrm{nm})\end{array}$ & $\begin{array}{l}\text { Electrical Conductivity } \sigma \\
\left(\mathbf{S} \cdot \mathrm{m}^{-1}\right)\end{array}$ & $\begin{array}{c}\text { Biocompatibility } \\
\text { (Cell Source/Methods Used) }\end{array}$ & Main Outcomes & Ref \\
\hline Silk fibroin/PEDOT nanofibers & $\begin{array}{l}\text { Vapor-phase } \\
\text { polymerization of } \\
\text { EDOT }\end{array}$ & $510-590$ & 4000 & $\begin{array}{l}\text { Human unrestricted somatic stem cells } \\
\text { (hUSSCs)/MTT assay, fluorescence } \\
\text { imaging, H\&E staining and gene } \\
\text { expression (RT-qPCR) }\end{array}$ & $\begin{array}{l}\text { - Ligament-like scaffold: construct of Silk fibroin/PEDOT } \\
\text { bilayer nanofibrous scaffold to mimic the aligned collagen } \\
\text { fiber bundles and Chitosan sponge coating to mimic the } \\
\text { glycosaminoglycans of ECM sheath } \\
\text { Electrical stimulation (DC electric pulses) facilitates cell } \\
\text { adhesion, proliferation and the expression of genes involved in } \\
\text { the healing process (collagen I, collagen III, decorin, biglycan } \\
\text { and aggrecan) }\end{array}$ & [55] \\
\hline
\end{tabular}




\subsection{Cell Viability and Proliferation on PEDOT:PSS-Coated PBI Electrospun Scaffolds}

In order to assess the biocompatibility of the electrospun scaffolds produced, hBMMSCs were cultured for 7 days on the surface of the three scaffold types prepared: pristine electrospun PBI fibers, cross-linked PEDOT:PSS-spin coated PBI fibers and cross-linked PEDOT:PSS-dip coated PBI fibers. The results of the MTT assay performed at days 1 and 7 post-seeding are shown in Figure 3. The data obtained show an increase in the number of cells for all the samples over the 7-day period, including the control glass coverslip samples. While at day 1 the cells seeded on cross-linked PEDOT:PSS-spin coated PBI fibers and PEDOT:PSS-dip coated PBI fibers showed a lower conversion of formazan with respect to the ones seeded on pristine PBI fibers, at day 7 the metabolic activity of cells cultured on PEDOT:PSS-coated scaffolds was similar to the ones on the non-coated PBI scaffolds. Accordingly, the fold increase in cell number from day 1 to day 7 was identical in the cross-linked PEDOT:PSS-coated scaffolds (1.6 and 1.7 for spin and dip coated, respectively) and slightly higher than the one for non-coated fibers (1.2). The results at day 7 suggest the presence of a higher (but not statistically significant) number of cells in the PEDOT:PSS-spin coated scaffolds in comparison to the other electrospun scaffolds assessed. This behavior can be explained by the difference in the surface wettability of the scaffolds assessed by contact angle analysis. The contact angle analysis showed that PEDOT:PSS coating increases the hydrophobicity of the PBI fibers, with PEDOT:PSS-spin coated samples more hydrophilic than the PEDOT:PSS-dip coated ones. (see Figure S2 in supplementary data).

MTT Assay

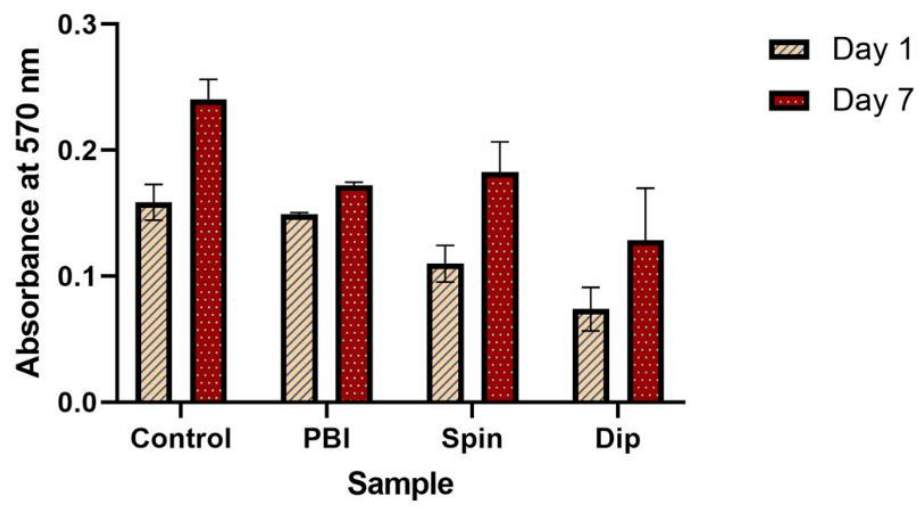

Figure 3. MTT assay results performed after 1 and 7 days of hBM-MSCs culture on the three types of scaffolds: pristine electrospun PBI fibers, PEDOT:PSS-spin coated PBI fibers and PEDOT:PSS-dip coated PBI fibers. Tissue culture plates were used as controls. Results are expressed as mean \pm standard deviation ( $n=3$ independent samples).

To the best of our knowledge, this is the first study combining MSCs with PBI-based electrospun fibers. Nevertheless, other studies have demonstrated the biocompatibility of PEDOT-containing nanofibers for MSCs [48,49]. Abedi et al. fabricated and characterized chitosan/PEDOT:PSS nanofibers, which were found to be highly biocompatible when cultured with rat BM-MSCs [48]. Additionally, Chen et al. reported high hMSCs viability when cultured for 7 days on bacterial cellulose/PEDOT:PSS nanofibers with moderate PSS doping concentrations below $0.05 \mathrm{M}$ [49].

hBM-MSCs' viability and proliferation on the electrospun scaffolds were further confirmed through calcein staining at day 1 and day 7 (Figure 4). The results are in accordance with the MTT assay, as the cells showed high viability and were able to grow on all the tested samples. Particularly, on pristine PBI and cross-linked PEDOT:PSS-spin coated PBI electrospun scaffolds, cells proliferated until reaching almost confluence, whereas in the case of cross-linked PEDOT:PSS-dip coated scaffolds, a lower cell proliferation was observed, possibly due to its higher hydrophobicity (see Figure S2 in supplementary data). Accordingly, a study performed by Birhanu et al. demonstrated that adipose-derived MSCs 
presented a significantly lower proliferative capacity on hydrophobic poly (L-lactic acid) (PLLA) nanofibers in comparison to plasma-treated hydrophilic PLLA scaffolds [56].

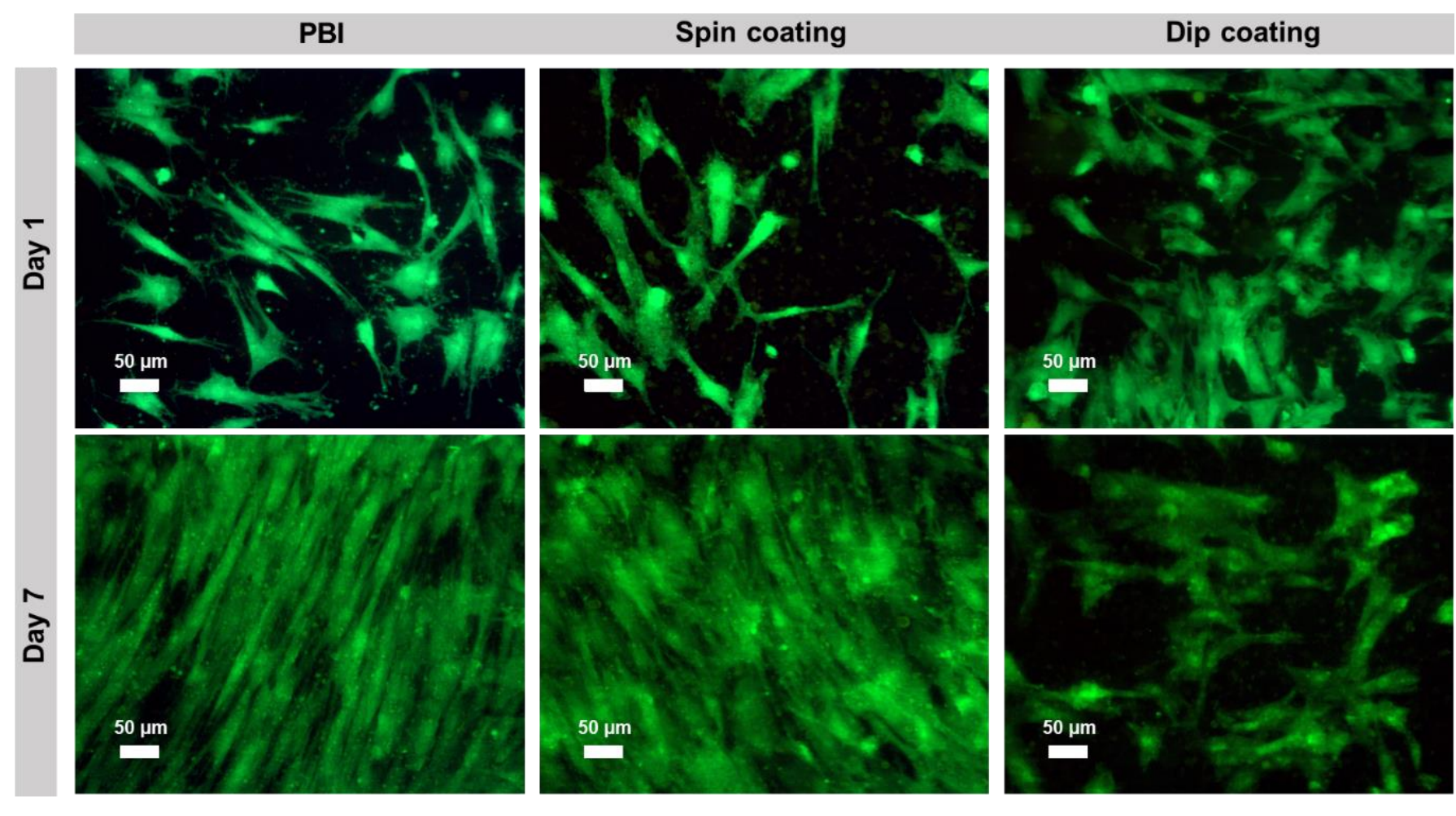

Figure 4. Calcein fluorescence staining of hBM-MSCs cultured on pristine electrospun PBI, PEDOT:PSS-spin coated PBI fibers and PEDOT:PSS-dip coated PBI fibers at days 1 and 7. Viable cells are stained in green. Scale bar: $50 \mu \mathrm{m}$.

\subsection{Evaluation of hBM-MSC' Morphology on PEDOT:PSS-Coated PBI Electrospun Scaffolds}

The morphology of the cells cultured on pristine electrospun PBI, cross-linked PEDOT: PSS-spin coated PBI fibers and cross-linked PEDOT:PSS-dip coated PBI fibers was assessed by DAPI/Phalloidin staining at days 1 and 7. Fluorescence images of the DAPI/Phalloidin staining are shown in Figure 5. The results of DAPI/Phalloidin staining are in accordance with the results presented in Figures 3 and 4 . As it is possible to observe in Figure 5, the number of hBM-MSCs increased from day 1 to day 7 on PBI fibers and on cross-linked PEDOT:PSS-spin coated PBI fibers. In the cross-linked PEDOT:PSS-dip coated PBI samples, the cell proliferation levels were lower in comparison to the other scaffold conditions. Despite these differences, in all the scaffold conditions, cells were able to spread and display the typical elongated morphology of undifferentiated MSCs, with well-developed actin cytoskeleton. No particular direction of elongation can be determined, which it is consistent with the random nature of the nanofibers mat. Chen et al. had similar results on bacterial cellulose nanofibers coated with PEDOT:PSS. In their study, after 7 days of culture, the MSCs stretched their morphology on the nanofibers and proliferated on all PEDOT-coated samples [49].

In summary, none of the manufactured nanofibers meshes displayed any sign of cytotoxicity and they were all able to support hBM-MSCs proliferation, while providing, at the same time, an advantageous 3D ECM-like environment for cells. Although both coating methods resulted in similar fold increase in cell number over the 7 days culture period, cross-linked PEDOT:PSS-spin coated fibers promoted higher levels of cell adhesion and higher final cell numbers. However, cross-linked PEDOT:PSS-dip coated fibers are significantly more electrically conductive, which may be beneficial for some applications. As future work, we intend to assess the produced PEDOT:PSS-coated PBI fibers coupled with an external electrical stimulation envisaging bone and cartilage tissue engineering applications. For example, Zhu et al. [57] have demonstrated that the proliferation and 
osteogenic differentiation of hMSCs were enhanced by the application of an electrical stimulation on conductive nanofibers made of poly (L-lactic acid) (PLLA) containing multi-walled carbon nanotubes (MWCNTs). Moreover, hMSCs were able to elongate in the direction of the electrical field. Accordingly, we expect that electrospun scaffolds containing both nanoscale features and electrical conductivity will be highly effective in actively modulating cell functions.

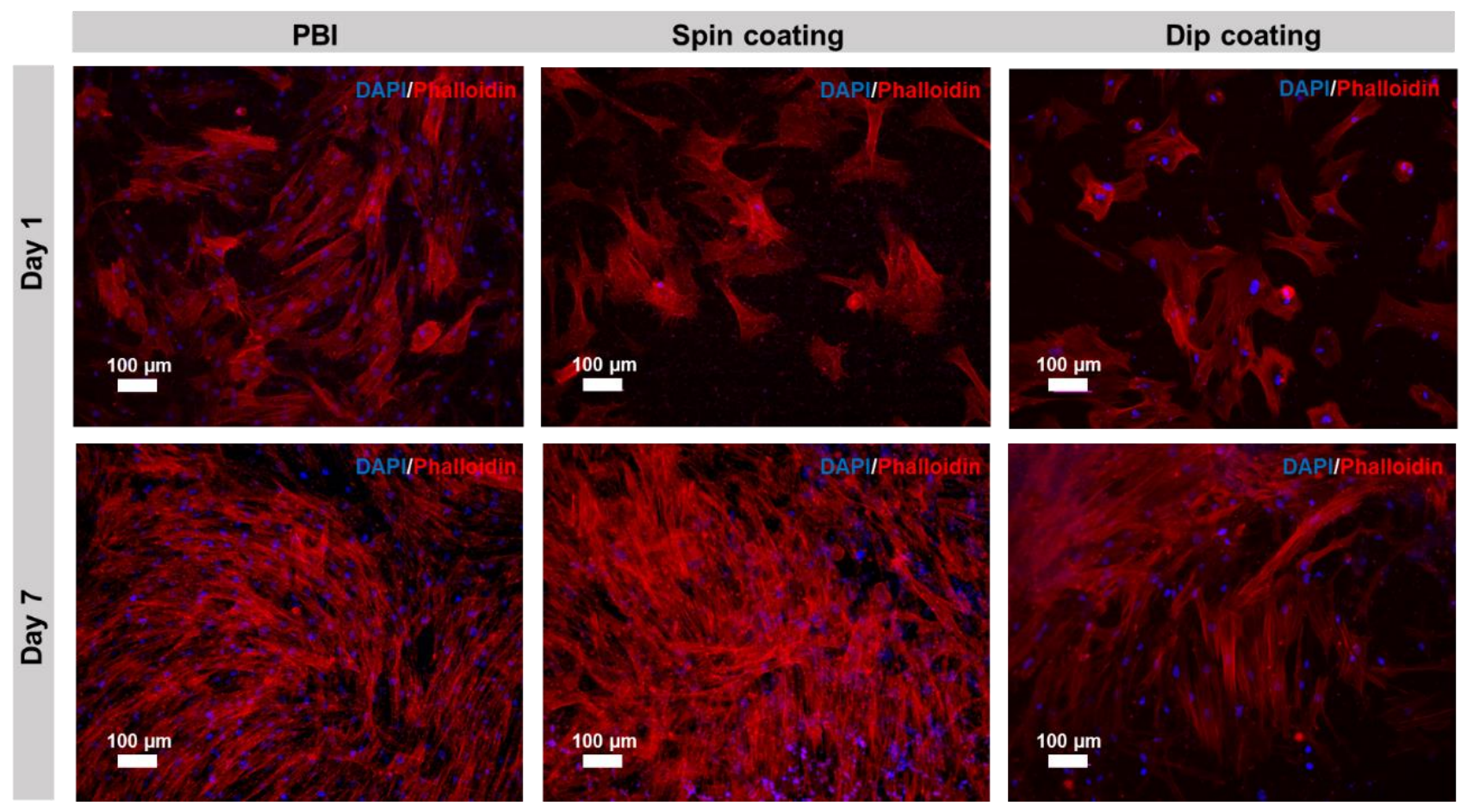

Figure 5. DAPI/Phalloidin immunofluorescence staining of hBM-MSCs cultured on pristine electrospun PBI, PEDOT:PSSspin coated PBI fibers and PEDOT:PSS-dip coated PBI fibers for days 1 and 7. DAPI stains cell nuclei blue, while Phalloidin stains actin-rich cytoskeleton red. Scale bar: $100 \mu \mathrm{m}$.

\section{Conclusions}

In this work, we developed and characterized a novel electrical conductive and biocompatible scaffold composed of PEDOT:PSS-coated PBI nanofibers. PBI nanofibers were efficiently produced by electrospinning and coated with PEDOT:PSS cross-linked with GOPS to enhance their electrical conductivity. Two different coating methods were compared: spin coating and dip coating. The obtained electrospun scaffolds showed increased fiber diameters, presenting an average of $256 \pm 59 \mathrm{~nm}$ for the spin coated PBI fibers and $279 \pm 54 \mathrm{~nm}$ for the dip coated PBI fibers. Electrical conductivity measurements demonstrated that the coating highly increased the scaffolds' electrical conductivity, with respect to the pristine PBI fiber mats, reaching $28.3 \mathrm{~S} \cdot \mathrm{m}^{-1}$ for PEDOT:PSS-spin coated and $147 \mathrm{~S} \cdot \mathrm{m}^{-1}$ for dip coated electrospun scaffolds, respectively. Additionally, all the developed scaffolds were able to support hBM-MSCs' adhesion, viability and proliferation. In particular, PBI nanofibers spin coated with cross-linked PEDOT:PSS displayed both electrical conductivity and high biocompatibility. Therefore, PEDOT:PSS-spin coated PBI scaffolds are considered to be the best candidates for further studies envisaging the development of novel tissue engineering substitutes, reliable in vitro models or new electrodes for in vivo electrical stimulation protocols.

Supplementary Materials: The following are available online at https:/ /www.mdpi.com/article/10 .3390 / polym13162786/s1, Table S1: TGA values for the onset and peaks temperatures, respective mass loss and remaining residue for the degradation steps observed in the samples tested in this work, Figure S1 (A) ATR-FTIR spectra, (B) Thermogravimetric analysis (TGA) (20\% oxygen) and (C) 
respective first derivative of the various samples produced in this work, Figure S2. Contact angle analysis of pristine electrospun PBI fibers, cross-linked PEDOT:PSS-spin coated PBI electrospun fibers, cross-linked PEDOT:PSS-dip coated PBI electrospun fibers and cross-linked PEDOT:PSS films.

Author Contributions: Original idea: L.S., F.C.F. and J.M. Experimental plan: L.S., J.C.S., F.F.F.G., C.A.V.R., F.C.F., J.M. Experimental work on materials: L.S. assisted by F.C.F. and J.M. Experimental work with cell culture: L.S. assisted by J.C.S. and F.C.F. Cell characterization: L.S. assisted by J.C.S., C.A.V.R. and F.C.F. ATR-FTIR analysis: F.F.F.G., A.C.M. Data analysis and figure preparation: L.S. with guidance by J.C.S., C.A.V.R., F.F.F.G., J.M. and F.C.F. Scientific guidance and discussions, laboratory space and funding: C.A.V.R., R.J.L. J.M.S.C., F.C.F., J.M. Manuscript writing, original draft: L.S., J.C.S. and F.F.F.G. Writing-review and editing: C.A.V.R., R.J.L., J.M.S.C., J.M., F.C.F. All authors have read and agreed to the published version of the manuscript.

Funding: The authors acknowledge funding from FCT-Portuguese Foundation for Science and Technology (FCT/MCTES), with dedicated funding from NEURON grant (PTDC/CTM-CTM/30237/2017) and also FCT/MCTES funding to iBB (UIDB/04565/2020 and UIDP/04565/2020), IT (UIDB/50008/ 2020), CERENA (UIDB/04028/2020) and i4HB (LA/P/0140/2020) and of Post-Doc grant SFRH/BPD/ 82056/2011 and PhD scholarship (PD/BD/114045/2015), as well as funding from POR Lisboa 2020 through the grant PRECISE (Project N. 16394).

Institutional Review Board Statement: Not applicable.

Informed Consent Statement: Human mesenchymal stromal cells samples were obtained from healthy donors after written informed consent according to the Directive 2004/23/EC-European Council, on setting standards of quality and safety for the donation, procurement, testing, processing, preservation, storage and distribution of human tissues and cells (Portuguese Law22/2007), with the approval of the Ethics Committee of the respective clinical institution. Data anonymization was ensured by the clinical institution before cells were received by the authors.

Data Availability Statement: Data available on request.

Acknowledgments: Thanks to Isabel Nogueira for technical support on SEM image acquisition at MicroLab facilities at IST Lisbon and Flávio Ferreira for the dilution of the casting PBI solution.

Conflicts of Interest: The authors declare no conflict of interest.

\section{References}

1. Tyler, S.E.B. Nature's Electric Potential: A Systematic Review of the Role of Bioelectricity in Wound Healing and Regenerative Processes in Animals, Humans, and Plants. Front. Physiol. 2017, 8, 627. [CrossRef] [PubMed]

2. Levin, M. Molecular bioelectricity: How endogenous voltage potentials control cell behavior and instruct pattern regulation in vivo. Mol. Biol. Cell 2014, 25, 3835-3850. [CrossRef] [PubMed]

3. Erickson, C.A.; Nuccitelli, R. Embryonic fibroblast motility and orientation can be influenced by physiological electric fields. J. Cell Biol. 1984, 98, 296-307. [CrossRef] [PubMed]

4. Ferrier, J.; Ross, S.M.; Kanehisa, J.; Aubin, J.E. Osteoclasts and osteoblasts migrate in opposite directions in response to a constant electrical field. J. Cell. Physiol. 1986, 129, 283-288. [CrossRef]

5. Aaron, R.K.; Ciombor, D.M.; Wang, S.; Simon, B. Clinical Biophysics: The Promotion of Skeletal Repair by Physical Forces. Ann. N. Y. Acad. Sci. 2006, 1068, 513-531. [CrossRef] [PubMed]

6. Banks, T.A.; Luckman, P.S.B.; Frith, J.; Cooper-White, J.J. Effects of electric fields on human mesenchymal stem cell behaviour and morphology using a novel multichannel device. Integr. Biol. 2015, 7, 693-712. [CrossRef]

7. Motaln, H.; Schichor, C.; Lah, T.T. Human mesenchymal stem cells and their use in cell-based therapies. Cancer 2010, 116, 2519-2530. [CrossRef]

8. Oliveira, K.M.C.; Leppik, L.; Keswani, K.; Rajeev, S.; Bhavsar, M.B.; Henrich, D.; Barker, J.H. Electrical Stimulation Decreases Dental Pulp Stem Cell Osteo-/Odontogenic Differentiation. BioResearch Open Access 2020, 9, 162-173. [CrossRef]

9. Baker, B.; Becker, R.O.; Spadaro, J. A Study of Electrochemical Enhancement of Articular Cartilage Repair. Clin. Orthop. Relat. Res. 1974, 102, 251-267. [CrossRef]

10. Baker, B.; Spadaro, J.; Marino, A.; Becker, R.O. Electrical stimulation of articular cartilage regeneration. Ann. N. Y. Acad. Sci. 1974, 238, 491-499. [CrossRef]

11. Tandon, B.; Magaz, A.; Balint, R.; Blaker, J.; Cartmell, S.H. Electroactive biomaterials: Vehicles for controlled delivery of therapeutic agents for drug delivery and tissue regeneration. Adv. Drug Deliv. Rev. 2018, 129, 148-168. [CrossRef]

12. Nezakati, T.; Seifalian, A.; Tan, A.; Seifalian, A. Conductive Polymers: Opportunities and Challenges in Biomedical Applications. Chem. Rev. 2018, 118, 6766-6843. [CrossRef] 
13. Palza, H.; Zapata, P.A.; Angulo-Pineda, C. Electroactive Smart Polymers for Biomedical Applications. Materials 2019, $12,277$. [CrossRef]

14. Tomczykowa, M.; Plonska-Brzezinska, M.E. Conducting Polymers, Hydrogels and Their Composites: Preparation, Properties and Bioapplications. Polymers 2019, 11, 350. [CrossRef]

15. Kaur, G.; Adhikari, R.; Cass, P.; Bown, M.; Gunatillake, P. Electrically conductive polymers and composites for biomedical applications. RSC Adv. 2015, 5, 37553-37567. [CrossRef]

16. Pires, F.; Ferreira, Q.; Rodrigues, C.A.; Morgado, J.; Ferreira, F.C. Neural stem cell differentiation by electrical stimulation using a cross-linked PEDOT substrate: Expanding the use of biocompatible conjugated conductive polymers for neural tissue engineering. Biochim. Biophys. Acta 2015, 1850, 1158-1168. [CrossRef]

17. Li, W.-J.; Laurencin, C.T.; Caterson, E.J.; Tuan, R.S.; Ko, F.K. Electrospun nanofibrous structure: A novel scaffold for tissue engineering. J. Biomed. Mater. Res. 2002, 60, 613-621. [CrossRef] [PubMed]

18. Bhardwaj, N.; Kundu, S.C. Electrospinning: A fascinating fiber fabrication technique. Biotechnol. Adv. 2010, 28 , 325-347. [CrossRef] [PubMed]

19. Ingavle, G.C.; Leach, J.K. Advancements in Electrospinning of Polymeric Nanofibrous Scaffolds for Tissue Engineering. Tissue Eng. Part B Rev. 2014, 20, 277-293. [CrossRef] [PubMed]

20. Silva, J.C.; Udangawa, R.N.; Chen, J.; Mancinelli, C.D.; Garrudo, F.F.F.; Mikael, P.E.; Cabral, J.M.S.; Ferreira, F.C.; Linhardt, R.J. Kartogenin-loaded coaxial PGS/PCL aligned nanofibers for cartilage tissue engineering. Mater. Sci. Eng. C Mater Biol Appl. 2020, 107, 110291. [CrossRef] [PubMed]

21. Garrudo, F.F.F.; Chapman, C.A.; Hoffman, P.R.; Udangawa, R.N.; Silva, J.C.; Mikael, P.E.; Rodrigues, C.A.V.; Cabral, J.M.S.; Morgado, J.M.F.; Ferreira, F.C.; et al. Polyaniline-polycaprolactone blended nanofibers for neural cell culture. Eur. Polym. J. 2019, 117, 28-37. [CrossRef]

22. Chen, M.-C.; Sun, Y.-C.; Chen, Y.-H. Electrically conductive nanofibers with highly oriented structures and their potential application in skeletal muscle tissue engineering. Acta Biomater. 2013, 9, 5562-5572. [CrossRef]

23. Rajasekaran, R.; Seesala, V.S.; Sunka, K.C.; Ray, P.G.; Saha, B.; Banerjee, M.; Dhara, S. Role of nanofibers on MSCs fate: Influence of fiber morphologies, compositions and external stimuli. Mater. Sci. Eng. C Mater. Biol. Appl. 2020, 107, 110218. [CrossRef] [PubMed]

24. Zhou, J.; Cheng, L.; Sun, X.; Wang, X.; Jin, S.; Li, J.; Wu, Q. Neurogenic differentiation of human umbilical cord mesenchymal stem cells on aligned electrospun polypyrrole/polylactide composite nanofibers with electrical stimulation. Front. Mater. Sci. 2016, 10, 260-269. [CrossRef]

25. Prabhakaran, M.P.; Ghasemi-Mobarakeh, L.; Jin, G.; Ramakrishna, S. Electrospun conducting polymer nanofibers and electrical stimulation of nerve stem cells. J. Biosci. Bioeng. 2011, 112, 501-507. [CrossRef]

26. Garrudo, F.; Udangawa, R.; Hoffman, P.; Sordini, L.; Chapman, C.; Mikael, P.; Ferreira, F.C.; Silva, J.C.; Rodrigues, C.A.; Cabral, J.M.; et al. Polybenzimidazole nanofibers for neural stem cell culture. Mater. Today Chem. 2019, 14, 100185. [CrossRef]

27. Sandor, R. PBI (Polybenzimidazole): Synthesis, Properties and Applications. High Perform. Polym. 1990, 2, 25-37. [CrossRef]

28. Dos Santos, F.; Andrade, P.Z.; Boura, J.S.; Abecasis, M.M.; da Silva, C.L.; Cabral, J.M. Ex vivo expansion of human mesenchymal stem cells: A more effective cell proliferation kinetics and metabolism under hypoxia. J. Cell. Physiol. 2009, 223, 27-35. [CrossRef]

29. Darvish, M.; Payandeh, Z.; Soleimanifar, F.; Taheri, B.; Soleimani, M.; Islami, M. Umbilical cord blood mesenchymal stem cells application in hematopoietic stem cells expansion on nanofiber three-dimensional scaffold. J. Cell. Biochem. 2019, 120, 12018-12026. [CrossRef] [PubMed]

30. Bagher, Z.; Ebrahimi-Barough, S.; Azami, M.; Safa, M.; Joghataei, M.T. Cellular activity of Wharton's Jelly-derived mesenchymal stem cells on electrospun fibrous and solvent-cast film scaffolds. J. Biomed. Mater. Res. Part A 2015, 104, 218-226. [CrossRef] [PubMed]

31. Jahangiri, S.; Aravi, İ.; Şanli, L.I.; Menceloğlu, Y.Z.; Özden-Yenigün, E. Fabrication and optimization of proton conductive polybenzimidazole electrospun nanofiber membranes. Polym. Adv. Technol. 2018, 29, 594-602. [CrossRef]

32. Ferreira, F.A.; Esteves, T.; Carrasco, M.P.; Bandarra, J.; Afonso, C.A.M.; Ferreira, F.C. Polybenzimidazole for active pharmaceutical ingredient purification: The Mometasone furoate case study. Ind. Eng. Chem. Res. 2019, 58, 10524-10532. [CrossRef]

33. Rao, S. Chapter 5-Adsorption. In Interface Science and Technology, Vincent Ball; Elsevier: Amsterdam, The Netherlands, 2018; Volume 21, pp. 251-331. [CrossRef]

34. Lü, L.-X.; Wang, Y.-Y.; Mao, X.; Xiao, Z.-D.; Huang, N.-P. The effects of PHBV electrospun fibers with different diameters and orientations on growth behavior of bone-marrow-derived mesenchymal stem cells. Biomed. Mater. 2012, 7, 015002. [CrossRef]

35. Jia, L.; Prabhakaran, M.P.; Qin, X.; Ramakrishna, S. Stem cell differentiation on electrospun nanofibrous substrates for vascular tissue engineering. Mater. Sci. Eng. C Mater. Biol. Appl. 2013, 33, 4640-4650. [CrossRef] [PubMed]

36. Yang, F.; Murugan, R.; Wang, S.; Ramakrishna, S. Electrospinning of nano/micro scale poly(L-lactic acid) aligned fibers and their potential in neural tissue engineering. Biomaterials 2005, 26, 2603-2610. [CrossRef] [PubMed]

37. Anandhan, S.; Ponprapakaran, K.; Senthil, T.; George, G. Parametric study of manufacturing ultrafine polybenzimidazole fibers by electrospinning. Int. J. Plast. Technol. 2012, 16, 101-116. [CrossRef]

38. Kuş, M.; Okur, S. Electrical characterization of PEDOT:PSS beyond humidity saturation. Sens. Actuators B Chem. 2009, 143, 177-181. [CrossRef] 
39. Dimitriev, O.; Grinko, D.; Noskov, Y.; Ogurtsov, N.; Pud, A. PEDOT:PSS films-Effect of organic solvent additives and annealing on the film conductivity. Synth. Met. 2009, 159, 2237-2239. [CrossRef]

40. Lee, S.H.; Park, H.; Son, W.; Choi, H.H.; Kim, J.H. Novel solution-processable, dedoped semiconductors for application in thermoelectric devices. J. Mater. Chem. A 2014, 2, 13380-13387. [CrossRef]

41. Mengistie, D.A.; Chen, C.-H.; Boopathi, K.M.; Pranoto, F.W.; Li, L.-J.; Chu, C.-W. Enhanced Thermoelectric Performance of PEDOT:PSS Flexible Bulky Papers by Treatment with Secondary Dopants. ACS Appl. Mater. Interfaces 2014, 7, 94-100. [CrossRef]

42. Solazzo, M.; Krukiewicz, K.; Zhussupbekova, A.; Fleischer, K.; Biggs, M.J.; Monaghan, M.G. PEDOT:PSS interfaces stabilised using a PEGylated crosslinker yield improved conductivity and biocompatibility. J. Mater. Chem. B 2019, 7, 4811-4820. [CrossRef]

43. Håkansson, A.; Han, S.; Wang, S.; Lu, J.; Braun, S.; Fahlman, M.; Berggren, M.; Crispin, X.; Fabiano, S. Effect of (3glycidyloxypropyl)trimethoxysilane (GOPS) on the electrical properties of PEDOT:PSS films. J. Polym. Sci. Part B Polym. Phys. 2017, 55, 814-820. [CrossRef]

44. Le, T.-H.; Kim, Y.; Yoon, H. Electrical and Electrochemical Properties of Conducting Polymers. Polymers 2017, 9, 150. [CrossRef] [PubMed]

45. Sordini, L.; Garrudo, F.F.F.; Rodrigues, C.A.V.; Linhardt, R.J.; Cabral, J.M.S.; Ferreira, F.C.; Morgado, J. Effect of Electrical Stimulation Conditions on Neural Stem Cells Differentiation on Cross-Linked PEDOT:PSS Films. Front. Bioeng. Biotechnol. 2021, 9 , 73. [CrossRef] [PubMed]

46. Tian, F.; Hosseinkhani, H. Quantitative analysis of cell adhesion on aligned micro- and nanofibers. J. Biomed. Mater. Res. 2008, 84A, 291-299. [CrossRef]

47. Chen, M.; Patra, P.K.; Warner, S.B.; Bhowmick, S. Role of Fiber Diameter in Adhesion and Proliferation of NIH 3 T3 Fibroblast on Electrospun Polycaprolactone Scaffolds. Tissue Eng. 2007, 13, 579-587. [CrossRef]

48. Abedi, A.; Hasanzadeh, M.; Tayebi, L. Conductive nanofibrous Chitosan/PEDOT:PSS tissue engineering scaffolds. Mater. Chem. Phys. 2019, 237, 121882. [CrossRef]

49. Chen, C.; Yu, Y.; Li, K.; Zhao, M.; Liu, L.; Yang, J.; Liu, J.; Sun, D. Facile approach to the fabrication of 3D electroconductive nanofibers with controlled size and conductivity templated by bacterial cellulose. Cellulose 2015, 22, 3929-3939. [CrossRef]

50. Lay, M.; Pèlach, M. Àngels; Pellicer, N.; Tarrés, Q.; Bun, K.N.; Vilaseca, F. Smart nanopaper based on cellulose nanofibers with hybrid PEDOT:PSS/polypyrrole for energy storage devices. Carbohydr. Polym. 2017, 165, 86-95. [CrossRef]

51. Kiristi, M.; Oksuz, A.U.; Oksuz, L.; Ulusoy, S. Electrospun chitosan/PEDOT nanofibers. Mater. Sci. Eng. C 2013, 33, 3845-3850. [CrossRef]

52. Du, L.; Li, T.; Jin, F.; Wang, Y.; Li, R.; Zheng, J.; Wang, T.; Feng, Z.-Q. Design of high conductive and piezoelectric poly (3,4ethylenedioxythiophene)/chitosan nanofibers for enhancing cellular electrical stimulation. J. Colloid Interface Sci. 2020, 559, 65-75. [CrossRef] [PubMed]

53. Choi, G.M.; Lim, S.-M.; Lee, Y.-Y.; Yi, S.-M.; Lee, Y.-J.; Sun, J.-Y.; Joo, Y.-C. PEDOT:PSS/Polyacrylamide Nanoweb: Highly Reliable Soft Conductors with Swelling Resistance. ACS Appl. Mater. Interfaces 2019, 11, 10099-10107. [CrossRef]

54. Jin, L.; Wang, T.; Feng, Z.-Q.; Leach, M.K.; Wu, J.; Mo, S.; Jiang, Q. A facile approach for the fabrication of core-shell PEDOT nanofiber mats with superior mechanical properties and biocompatibility. J. Mater. Chem. B 2013, 1, 1818-1825. [CrossRef]

55. Dodel, M.; Nejad, N.H.; Bahrami, H.; Soleimani, M.; Amirabad, L.M.; Hanaee-Ahvaz, H.; Atashi, A. Electrical stimulation of somatic human stem cells mediated by composite containing conductive nanofibers for ligament regeneration. Biologicals 2017, 46, 99-107. [CrossRef]

56. Birhanu, G.; Javar, H.A.; Seyedjafari, E.; Zandi-Karimi, A.; Telgerd, M.D. An improved surface for enhanced stem cell proliferation and osteogenic differentiation using electrospun composite PLLA/P123 scaffold. Artif. Cells Nanomed. Biotechnol. 2018, 46, 1274-1281. [CrossRef] [PubMed]

57. Zhu, S.; Jing, W.; Hu, X.; Huang, Z.; Cai, Q.; Ao, Y.; Yang, X. Time-dependent effect of electrical stimulation on osteogenic differentiation of bone mesenchymal stromal cells cultured on conductive nanofibers. J. Biomed. Mater. Res. Part A 2017, 105A, 3369-3383. [CrossRef] 